\title{
Interculturalismo quebequense: ¿versión del multiculturalismo canadiense o modelo con estructura institucional propia?
}

\author{
Quebec interculturalism: a version of Canadian multiculturalism or
} a model with an institutional structure?

\author{
Isabel Wences / iwences@polsoc.uc3m.es \\ Universidad Carlos III de Madrid, España
}

\begin{abstract}
The aim of this article is to examine whether the political model for the management of diversity in Quebec is a particular or provincial manifestation of AngloCanadian multiculturalism or if, on the contrary, this nation has endowed itself with some tools and mechanisms which make it viable to sustain that it has designed a distinctive institutional structure and model of citizenship which a number of authors have named interculturalism. The article concludes holding such statement. To achieve this aim, this article analyzes the way both Canada and Quebec have dealt with the challenge of managing this living together in culturally plural societies and how this challenge has influenced their relationship.
\end{abstract}

Key words: interculturalism, multiculturalism, integration, cultural diversity, citizenship.

Resumen: El objetivo central de este trabajo consiste en examinar si el modelo interculturalista de gestión de la diversidad instaurado en Quebec es una manifestación particular o local del multiculturalismo anglocanadiense o si, por el contrario, consiste en un modelo autónomo vinculado al proyecto político de diseño de una estructura institucional distinta y de configuración de una ciudadanía diferenciada. Para alcanzar este objetivo se analizan los presupuestos normativos que subyacen a la manera en que tanto Canadá como Quebec han afrontado el reto de gestionar la convivencia en sociedades culturalmente plurales y cómo este desafío ha influido la relación entre ambas.

Palabras clave: interculturalismo, multiculturalismo, integración, diversidad cultural, ciudadanía. 


\section{Introducción}

Hoy en día diversos fenómenos inciden en el incremento y extensión de la diversidad cultural, al tiempo que se van produciendo manifestaciones políticas y jurídicas solicitando el reconocimiento de minorías culturales, muchas de las cuales durante largo tiempo han permanecido arrinconadas. Las diferencias culturales en un mismo espacio plantean numerosos retos y preguntas complejas sobre la convivencia. Cualquier respuesta debe tener claro, antes de nada, que las soluciones no pueden ser uniformes. Los desafíos que suponen el reconocimiento y acomodo de identidades culturales diversas y la inclusión de derechos en sistemas constitucionales democráticos requieren de profundas transformaciones institucionales.

Para que estas incursiones lleguen a buen puerto, es necesario adoptar un enfoque contextual que permita tomar en cuenta el escenario social y las aspiraciones políticas y de reconocimiento que ambiciona una comunidad concreta. Se debe estudiar caso por caso y encontrar medidas que vayan más allá de las posiciones que niegan la constitución de los sujetos singulares y de las posturas que rechazan las particularidades identitarias. Encontrar vías entre estos dos extremos debería ser uno de los objetivos centrales de nuestras actuales democracias occidentales.

Canadá y Quebec participaron del extendido ideal moderno que se ha caracterizado durante mucho tiempo por una serie de políticas -lingüísticas, culturales, de inmigración, educativas- que han favorecido la uniformidad, la simetría y la homogeneidad. Sin embargo, en las últimas décadas estas dos naciones y otras latitudes del mundo occidental han comenzado a aceptar que gran parte de los Estados son tanto plurinacionales - al acoger en su seno más de una cultura nacional-, como pluriculturales, pues en ellos se dan cita diversas culturas.

Esta condición ha ocasionado que en las últimas décadas surgieran notables esfuerzos académicos y políticos, con el fin de superar dicha condición monista y de diseñar arreglos políticos capaces de hacer viable el entendimiento y, más allá de la mera tolerancia, la convivencia mutua.

En el marco de estas iniciativas, en el presente artículo los objetivos serán: analizar la manera en que tanto Canadá como Quebec han afrontado este reto y cómo ello ha influido en la relación entre ambas naciones; así como indagar si el modelo político de gestión de la diversidad en Quebec es una manifestación particular o local del multiculturalismo anglocanadiense, o si, por el contrario, consiste en un modelo autónomo vinculado al proyecto político de diseño de una estructura institucional y de una configuración de una ciudadanía diferenciada. 
Es posible adelantar una conclusión. Se constata la existencia de elementos que inclinan la balanza del lado de esta última afirmación, pero todavía hay importantes desafíos en la consolidación de un modelo político y normativo particular y diferente del ya citado multiculturalismo. A su vez, esta constatación nos lleva a preguntarnos por qué Quebec decide adoptar un modelo propio de gestión de la diversidad cultural si ya existe un modelo en el país: el del multiculturalismo canadiense.

Dos cuestiones centrales acompañan a los objetivos antes planteados y se les dará atención en este trabajo. Primera, el análisis del multiculturalismo y del interculturalismo en tanto medidas, acciones y programas gubernamentales cuyo propósito es gestionar la diversidad cultural, la inmigración y la integración. Segunda, observar la propuesta teórica de algunos investigadores, particularmente filósofos, politólogos y sociólogos, como Bouchard (2012), Bouchard y Taylor (2008), Gagnon e Iacovino (2003) y Rocher y Labelle (2010), respecto a la orientación pluralista que consideran debería guiar la convivencia en la diversidad de los habitantes de Quebec y que no es el conocido modelo del multicuturalismo canadiense, sino lo que ellos han denominado el interculturalismo.

Este modelo enfatiza en el respeto a la diversidad; en la salvaguardia del principio del reconocimiento; en la integración con medidas que eviten la exclusión y la desigualdad social; en lógicas de armonización intercultural con base en el principio de la reciprocidad; en el diálogo entre identidades culturales; y en la construcción de una ciudadanía activa. Pero además apuesta por la reivindicación de elementos contextuales que autoricen la justificación de algunas dinámicas propias de una lógica particular, consistente en ser una condición minoritaria hacia el exterior -Quebec frente al Canadá anglófono y a una cultura anglosajona dominante en América del Norte- y mayoritaria hacia el interior -Quebec posee un grupo cultural francófono dominante(Laforest, 2010).

Para llevar a cabo estos objetivos se parte del análisis del doble estatus que acompaña a Quebec. Ello implica observar, por un lado, la relación entre el Canadá anglófono y el Quebec francófono, donde la política del multiculturalismo, el paradigma del reconocimiento y el debate del federalismo ocupan un lugar central; y, por el otro, las relaciones dentro del Quebec entre la cultura dominante y las minorías históricas que en ella convergen (anglófonos, indígenas autóctonos, inuits), así como la articulación que existe entre la inmigración reciente y la población establecida hace tiempo. 
Desde un punto de vista metodológico, este trabajo se enmarca en el ámbito de la Teoría Política aplicada, al tratar de proyectar las reflexiones teórico normativas sobre problemas o fenómenos de la vida política real, con el objeto de evaluar posteriormente los resultados obtenidos e incidir en la práctica política. La actividad académica de un teórico político es interpretar, valorar, aclarar y explicar las ideas, las justificaciones y las doctrinas del pensamiento político, así como problematizar y analizar críticamente cuestiones éticas, creencias políticas o preguntas máximas y diseñar mecanismos de actuación sobre la realidad (Wences, 2015).

Para ello, la Teoría Política utiliza un conjunto de instrumentos y cuenta con sus propias premisas epistemológicas. La Teoría Política se acompaña de una vertiente filosófica que tiene como finalidad identificar, interpretar, comprender y explicar los procesos políticos contemporáneos, así como los acuerdos y desacuerdos políticos; y además, conlleva el cometido de evaluar y especificar prácticas, principios e instituciones.

Esta vertiente le otorga a la Teoría Política una cualidad normativa que se ocupa de que haya correspondencia entre sus reflexiones axiológicas, las prácticas políticas y el diseño de instituciones. Asimismo, la Teoría Política se nutre de la historiografía de las ideas políticas, pues ésta le ayuda a configurar, condicionar y precisar los órdenes y las posibilidades de la vida política $\mathrm{y}$ ofrece herramientas para desafiar las visiones epistemológicas y discursivas que están asentadas y asumidas.

Además de lo filosófico normativo y lo historiográfico, la Teoría Política también puede ser aplicada, tal y como se considera en este trabajo. De acuerdo con ella, la Teoría Política orienta su actividad de manera que ésta pueda actuar sobre la realidad, con el fin de orientarla, modificarla y mejorarla, porque la Teoría Política no puede estar divorciada de la acción política (Taylor, 1983).

Finalmente, para poder dilucidar, comprender, explicar, criticar, interpretar y evaluar las prácticas políticas y actuar sobre ellas, la Teoría Política tiene también como quehacer aclarar y refinar conceptos del discurso político y, a su vez, valorar críticamente las creencias políticas (Heywood, 2010).

\section{Quebec y Canadá: tensiones y entendimientos}

Las relaciones entre Canadá y Quebec pueden ser analizadas desde diversos enfoques. Como bien subraya Alain-G. Gagnon (2003), es posible hacerlo mediante: 1) la observación de sus presupuestos legales; 2) a través del estudio del federalismo fiscal; o, como él prefiere, 3) desde las dimensiones his- 
tórico-institucionales de sus relaciones. Una cuarta posibilidad es -la cual, en combinación con la tercera, ensayaremos aquí- mediante el análisis de sus modelos de gestión de la diversidad cultural y de las relaciones que a partir de dichos modelos han tenido lugar entre ambas naciones.

Con base en estos dos últimos enfoques, la aproximación se divide en cuatro etapas: a) la relacionada con los fundamentos históricos y el establecimiento del primer orden constitucional; $b$ ) la de transición que alude a los años de 1960 a 1982; c) la que corre de 1982 -año de la llamada "repatriación" constitucional sin el consentimiento de Quebec- a la primera década del siglo $\mathrm{XXI}$, periodo en el cual tuvo lugar "la ruptura con el orden constitucional establecido y la emergencia de un nuevo orden político" (Gagnon, 2003: 139); y d) el periodo que contempla las relaciones que en los últimos años han tenido el gobierno federal y los distintos gobiernos quebequenses, hasta la llegada al poder tanto del primer ministro Philippe Couillard, del Parti Libéral du Québec (PLQ) -el 7 de abril de 2014-, como del primer ministro Justine Trudeau (Liberal Party), quien gobierna Canadá desde el 4 de noviembre de 2015.

Si se hace un apretado resumen, es posible ilustrar la primera etapa aludiendo a dos documentos de Estado que reflejan la identidad de Quebec dentro de Canadá: el Acta de Quebec de 1774 y el Acta de la América del Norte Británica (AANB) de 1867. El primero puede considerarse la Carta Magna de una política de la diversidad y del reconocimiento identitario canadiense y quebequense.

El AANB es una consecuencia lógica del Acta de Quebec y cobra relevancia porque ahí se formalizan dos cuestiones centrales para este trabajo; por un lado, el reconocimiento de los canadienses de ascendencia británica y los canadienses de ascendencia francesa; y, por el otro, el establecimiento de un principio federal pluralista. En cuanto a la primera cuestión, dada la época de su establecimiento, queda claro que la apertura cultural se limitaba a la identificación de los descendientes británicos y franceses; en consecuencia, otros grupos etnoculturales fueron relegados y apremiados a asimilarse a una u otra de las culturas monolíticas fundacionales, especialmente a la de origen británico.

Desde entonces y hasta 1971 el modelo canadiense de gestión de la diversidad cultural fue el de la anglo-conformidad. Por su parte, el principio federal pluralista daría lugar al establecimiento de dos tradiciones distintas del federalismo: el universalizante, que defiende la instauración de un poder central fuerte, y el comunitario (Gagnon, 2008). 
Con el paso del tiempo, estos dos modelos acompañarían la creciente confrontación entre dos proyectos nacionales: el canadiense y el quebequés. Queda constancia de ello en las palabras de Eugénie Brouillet (2008: 79): "Los canadienses de habla inglesa apoyan una evolución centralizadora de la federación canadiense y de la simetría en el plano de los poderes provinciales, mientras que los quebequenses defienden una mayor descentralización de los poderes y la instauración de un federalismo asimétrico".

El segundo periodo se caracteriza por ser de transición y va de la llamada Revolución tranquila a la repatriación de 1982. Es una etapa donde los actores sociales y políticos de Quebec adquieren un protagonismo central, iniciándose un proceso de afirmación en los terrenos social, económico, político y cultural. Este periodo resulta fundamental para comprender cómo se ha ido gestando la autonomía y cómo son actualmente las relaciones entre Quebec y Canadá.

Si bien se precisaría un análisis fino y extenso, aquí únicamente subrayaremos algunos acontecimientos centrales. En primer lugar, el establecimiento en 1963 de la Comisión Laurendeau-Dunton sobre el bilingüismo y el biculturalismo; el año anterior a la creación de esta comisión, el periodista André Laurendeau había expresado su inquietud por el acelerado crecimiento del discurso secesionista de Quebec y la indiferencia frente a este hecho por parte del Canadá anglófono. La versión definitiva del informe elaborado por esta comisión vio la luz en 1969 y a partir de él se asientan las bases de un principio de equidad entre Canadá y Quebec. Gagnon et al. (2013) señalan que a pesar del medio siglo que ha transcurrido desde los inicios de los trabajos de esta comisión, el marco que propuso para debatir la problemática cultural y lingüística de Canadá sigue vigente.

En segundo lugar, el otorgamiento del control del plan público de pensiones, lo que dotó a Quebec de gran autonomía fiscal y abrió las puertas para instaurar la Caja de Depósito e Inversión que terminaría siendo una de las fuentes más importantes de financiamiento público en Canadá.

En tercer lugar, la elección de Pierre Trudeau como líder del Parti Libéral federal en abril de 1968 y meses después como primer ministro de Canadá, lo cual significó el recrudecimiento de las relaciones con los gobiernos de Quebec, básicamente por su negativa a conceder a Quebec algo que no se le concedería a los otros estados miembros de la federación y que terminó con la repatriación de la Constitución.

El cuarto acontecimiento que nos permite comprender los cambios sociales y políticos que ocurrieron en el periodo que va de la llamada Revolución tranquila a la repatriación de 1982, es el papel desempeñado por 
Robert Bourassa, primer ministro de Quebec de 1970 a 1976 y de 1985 a 1993, quien impulsó la tesis del federalismo rentable, de la soberanía cultural y, posteriormente, de la soberanía compartida. No aspiraba a afianzar los deseos nacionalistas de Quebec en la Constitución, más bien apostó por revisar el sistema federal para otorgar a Quebec los recursos necesarios de cara al carácter bicultural de Canadá.

En quinto lugar, el reconocimiento por parte del gobierno de un "estatus especial” para Quebec, a la luz de la modificación del reparto federal de poderes, y del reconocimiento de la importancia para esta nación de la protección y promoción de intereses lingüísticos y culturales que exigía fuesen garantizados en la Constitución.

En sexto lugar, la elección de Rene Lévesque (1976-1985), de perfil autonomista, quien se comprometió a alcanzar la soberanía política absoluta, pero que no fue capaz de modificar la tendencia del gobierno federal a impulsar la repatriación de la Constitución con una fórmula de enmienda. Mientras que Lévesque preparaba la Carta de la Lengua Francesa que convertía al francés en la única lengua oficial, Trudeau trabajaba intensamente a favor de la unidad canadiense y la centralización de poderes.

Más tarde, en mayo de 1979 fue elegido el conservador Joe Clark, quien manifestó su disposición a aceptar un federalismo descentralizado y a concebir a Canadá como una "comunidad de comunidades"; pese a ello, el gobierno de Lévesque seguía empeñado en llevar a cabo un referendo sobre la soberaníaasociación, que convocó, finalmente, en mayo de 1980, y en el cual $60 \%$ de los electores votaron en contra. A pesar de esta derrota, Lévesque revalidó al año siguiente su cargo, mientras que el gobierno federal conservador minoritario se vio forzado a convocar elecciones, volviendo los liberales al poder; esto cerró las puertas a buscar vías para dar una respuesta política a la situación.

En 1982 todas las provincias, excepto Quebec, aceptaron el Acta Constitucional, cuya primera parte es la garantía constitucional de los derechos y libertades de los ciudadanos canadienses. Desde Quebec, la lectura era que lejos de otorgar reconocimiento se había repatriado la Constitución sin su consentimiento y que se había acordado, en ausencia del primer ministro Lévesque, la estipulación legal de una Carta de Derechos y Libertades, lo cual se interpretó como la consolidación de la visión centralizadora del federalismo y el inicio en Quebec de un proceso que Laforest (2014) ha denominado "exilio interior".

Algunos sintieron que se había impuesto unilateralmente un nuevo orden constitucional (Tully, 1999; Seymour, 1999); el ambiente político era hostil y el periodo de "transición, que comenzó al inicio de los años sesenta 
con el firme deseo de incluir a Quebec como un elemento fundamental en la federación, concluyó con una nota de exclusión, aislamiento y rechazo al reconocimiento" (Gagnon, 2003: 152-153).

De esta manera, en los inicios de la década de 1980 aumentaría notablemente la tensión entre el proyecto centralista y de reforzamiento de la identidad canadiense, por un lado; y el asimétrico y defensor de un reconocimiento político y jurídico para Quebec, por el otro. La apuesta de este último por un referéndum soberanista en 1980 endurecería aún más dicha tensión; ninguna autoridad política quebequense dio su consentimiento al Acta Constitucional de 1982; muchos percibieron esto como la imposición de un nacionalismo canadiense de carácter uniforme (Keating, 2001; Taylor, 1992). A partir de 1982, las decisiones políticas dependieron fuertemente de las enmiendas constitucionales, lo que desde determinados puntos de vista empobreció el constitucionalismo de Canadá (Brouillet, 2005).

El séptimo acontecimiento que afectó a las relaciones sociales y políticas entre Canadá y Quebec en el periodo que estamos analizando es la adopción, en 1971, por parte de la Cámara de los Comunes, del multiculturalismo como política oficial, iniciándose así el final del modelo del anglo-conformismo. Esta política pretendía, entre otras cosas, buscar vías para preservar las culturas minoritarias; facilitar la intervención de los miembros de los grupos culturales en la sociedad canadiense; apoyar los encuentros entre los grupos culturales en aras de la unidad nacional; y asegurar a los inmigrantes el aprendizaje de, al menos, una de las dos lenguas oficiales (Bauer, 1994).

El multiculturalismo se presentaba como una política de puertas abiertas a la inmigración, de protección de los derechos individuales de los miembros de las minorías etnoculturales y de lucha contra la discriminación étnica y racial. Sin embargo, las críticas a esta política provinieron de varios frentes. Por una parte, intelectuales del Canadá anglófono denunciaron que el acento en los particularismos étnicos y en la tolerancia, ignorando la aceptación y la integración, fomentaba la peligrosa formación de guetos y que, además, favorecía la conservación de valores tradicionales de dominación cultural, reduciendo la cultura a un mero folklore y a una mercancía (Bissoondath, 1995).

Por otra parte, académicos y políticos de Quebec consideraron que detrás de la apuesta por el multiculturalismo -y junto con ella del bilingüismo, y más tarde de la Carta de Derechos y Libertades y la igualdad formal de las provincias- no sólo había una perspectiva estrecha de la diversidad cultural, sino una estrategia para consolidar la identidad canadiense y negar la existencia de la nación quebequense (Labelle et al., 1995; Bourque et al., 2000). 
En este contexto, y de acuerdo con Helly (2005), tres razones explican, brevemente, el paso del biculturalismo al multiculturalismo. Primera, una respuesta a las reivindicaciones de los inmigrantes de sitios distintos a las provincias francesa o británica. Segunda, un factor distintivo de la identidad canadiense frente a la presencia angloestadounidense, de claro dominio cultural y económico. Y, tercera, una estrategia de unidad nacional dirigida a debilitar el nacionalismo quebequense (Helly, 2005); y, de acuerdo con algunos autores, como Donald Forbes (2007), hacer fracasar el movimiento separatista de Quebec.

Conviene subrayar que la crítica por parte de pensadores quebequenses, como Micheline Labelle, François Rocher y Guy Rocher (1995), hacia el multiculturalismo no significa una oposición al pluralismo y el abrazo al asimilacionismo; por el contrario, "se trata más bien del rechazo a un modelo de integración que niega la existencia de una comunidad política ya constituida en Quebec" (Labelle et al., 1995: 218).

En el Acta Constitucional de 1982 se incorporó el principio del multiculturalismo que había sido adoptado en 1971. El artículo 27 señala que toda interpretación del Acta debe hacerse de acuerdo con el objetivo de promover el mantenimiento y la valorización del patrimonio multicultural de los canadienses; se preserva y fomenta su herencia multicultural, siempre y cuando no entre en colisión con los derechos individuales. Los únicos derechos colectivos reconocidos son los concernientes a los canadienses francófonos, a las dos religiones mayoritarias de Canadá y los relativos a las primeras naciones.

Más tarde, en 1988, esta política fue reafirmada en la ley sobre el multiculturalismo canadiense que habrá de constituirse en una característica fundamental de la identidad y del patrimonio de Canadá. Queda así establecido el reconocimiento de la diversidad como un rasgo primordial de su sociedad; el afianzamiento como valores esenciales de los derechos y libertades individuales, la igualdad de los individuos y la existencia de dos lenguas oficiales; la preservación y valoración del patrimonio multicultural en el contexto de un igual acceso y participación de todos los canadienses a la vida económica, social, cultural y política, intentando superar la discriminación y los prejuicios.

Con base en esta ley, las instituciones federales tienen la obligación de dirigir sus actividades teniendo en cuenta la realidad multicultural de Canadá y en armonía con las peculiaridades nacionales, especialmente las dos lenguas oficiales.

A comienzos de la década de 1990 se creó el Ministerio de Multiculturalismo y Ciudadanía, lo cual representó la formulación de nuevos objetivos que tenían como misión, por un lado, promover entre los ciudadanos y entre 
las instituciones canadienses la apreciación y la aceptación de los principios del multiculturalismo así como su puesta en práctica; por el otro, ayudar a los canadienses a conservar, valorizar y compartir su cultura, su lengua y su identidad etnocultural; y finalmente, favorecer la entera y plena participación de la sociedad, tanto de los particulares como de los grupos que resultan de las minorías etnoculturales del Canadá.

En el otoño de 1993, los programas relativos al multiculturalismo formaron parte de un nuevo y más importante ministerio, el del Patrimonio Canadiense. Años después, en 1996, hubo un cambio en los objetivos programáticos y se puso el acento en los siguientes fines: "La construcción de una sociedad justa y equitativa, la participación cívica (que permite a los canadienses de todos los orígenes contribuir a labrar nuestra colectividad y nuestro país), y la identidad (favoreciendo una sociedad que reconoce, respeta y expresa la diversidad cultural con el fin de que las personas de todos los horizontes sientan que forman parte del Canadá)" (Leman, 1999: 7).

Lo anterior da cuenta de lo siguiente: mientras que en sus inicios los programas relativos al multiculturalismo fueron objeto de diversas controversias, especialmente provenientes de quienes lo calificaron de adjudicar un tinte étnico a las relaciones sociales y de fomentar la yuxtaposición de los grupos (Bissoondath, 1995), más tarde dichos programas evolucionaron hacia la integración social y económica, la eliminación de obstáculos discriminatorios, la reforma de las instituciones y las medidas de promoción social dirigidas a asegurar la igualdad de oportunidades.

Sin embargo, este cambio no ha estado exento de críticas por parte de académicos especialistas en diversidad cultural. Poco a poco -aseguran Rocher, Labelle, Field e Icar (2007) - el multiculturalismo, el cual era presentado como una ventaja comparativa en el plano económico y una innovación canadiense que inspiraría a varios países, fue reformado con el objeto de promover más la identidad canadiense que de preservar sus culturas.

Los críticos Rocher, Labelle, Field e Icar (2007) señalan que esta manera de entender y gestionar la diversidad cultural, entre otros asuntos, ignora los colonialismos francés y británico; oculta la existencia de las Primeras Naciones; niega el estatuto nacional de los quebequenses; separa lengua y cultura; y enmascara las desigualdades políticas y económicas que dividen a las diversas comunidades étnicas y nacionales.

A lo largo de los años siguientes del Acta Constitucional -enmarcados en lo que a efectos de este trabajo sería una tercera etapa- se hicieron distintos esfuerzos por encontrar una salida a la crisis política y constitucional; el entonces líder del Parti Libéral du Québec, Robert Bourassa, intentó llegar a 
diversos acuerdos con el gobierno central, encabezado por Brian Mulroney, jefe del Progressive Conservative Party de Canadá.

Entre dichos esfuerzos destacan las negociaciones del Lago Meech (1987-1990), que terminaron en fracaso; el nombramiento de la Comisión Bélanger-Campeau (1991), la cual tenía como propósito redefinir los arreglos políticos y constitucionales que regían el estatus de Quebec y sus relaciones con otros Estados miembros de la federación; y el Acuerdo de Charlottetown (1992), fruto de varios meses de negociaciones pero cuyo resultado no satisfizo las demandas de Quebec, especialmente la petición de su reconocimiento como sociedad distinta, su solicitud de derecho de veto sobre todo cambio constitucional y la pretensión de obtener garantías en materia de nombramiento de jueces quebequenses ante la Corte Suprema de Canadá.

Estos fracasos tuvieron como consecuencia el debilitamiento de las relaciones de confianza entre Quebec y el resto de las provincias canadienses, así como una movilización y reorganización de las fuerzas políticas en Quebec. En 1994, el Parti Québécois (PQ) ganó las elecciones, lo cual alentaría las intenciones a favor de la soberanía de Quebec; y por segunda vez en quince años, el 30 de octubre de 1995, se llevaría a cabo otro referendo que consultaría a los quebequenses sobre su futuro político.

A diferencia del referendo anterior, donde las fuerzas del "no" ganaron con casi $60 \%$ de los votos, en esta ocasión $94 \%$ de los votantes dieron como resultado $50.6 \%$ a favor del "no", respaldando, por tanto, un 49,4\% la opción de soberanía-asociación. Sólo hubo 54,228 votos de diferencia. Se mantuvo el statu quo constitucional, y aunque el gobierno federal de Jean Chrétien adoptó una resolución que afirmaba el carácter distinto de la sociedad quebequense dentro de Canadá, se siguió rechazando toda fórmula de federalismo asimétrico. Los siguientes años se caracterizaron por confrontaciones entre las jefaturas de Quebec y de Ottawa, al entrar en una fase de no reconocimiento y, de acuerdo con algunos puntos de vista, como la de Guy Laforest (2014), de debilitamiento democrático.

Durante los años posteriores, especialmente cuando gobernaron los liberales federales con Jean Chrétien y Paul Martin a la cabeza, se optó por una dinámica centralizadora, que, entre otros aspectos, controlaba el acceso a la financiación de los proyectos y determinaba el rumbo del gasto en competencias provinciales (como educación superior, investigación e innovación, infraestructuras, etc.). Con el tiempo, dicha dinámica se encontró con el rechazo de otras provincias como Alberta y la Columbia Británica, que se negaban a las políticas centralizadoras y a la intervención del Estado. 
Una nueva coalición de fuerzas respondería ante este panorama. Los conservadores encabezados por Stephen Harper llegaron al poder en 2006 con un discurso donde enarbolaban un federalismo de apertura. Al paso de los meses, este discurso se fue desdibujando, pero su contenido inicial apostaba por respetar las competencias de las provincias, ceñir el poder de gasto de la administración central, reconducir el desequilibrio fiscal y ofrecer a Quebec la posibilidad de tener una representación en organismos internacionales como la Unesco.

En noviembre de 2006 el Parlamento canadiense reconoció a Quebec como una nación desde un punto de vista cultural y social, pero no legal. Sin embargo, el gobierno liberal de Quebec, encabezado por Jean Charest, se caracterizó por un nulo entusiasmo para defender las iniciativas antes mencionadas y por la ausencia de reivindicaciones claras a la administración central.

El Parti Libéral du Québec se mantendría en el poder durante nueve años hasta que en septiembre de 2012 el Parti Québécois ganó, por escaso margen, las elecciones. Por primera vez, una mujer, Pauline Marois, se convertiría en primera ministra al obtener su partido cuatro escaños de ventaja en la Asamblea Nacional de Quebec. No obstante, tan sólo 18 meses después, su convicción de que "queremos un país y lo tendremos" se vio frustrada, y en abril de 2014 el PLQ regresaría al poder dirigido por Philippe Couillard.

Las relaciones en materia de gestión de la diversidad cultural entre el gobierno quebequense de Marois y el federal de Harper se tensarían a la luz de la iniciativa de la Charte des valeurs propuesta por el PQ. Sin embargo, nuevos horizontes de diálogo parecen abrirse con la llegada al poder de Couillard en Quebec y de Justin Trudeau en Canadá en el otoño de 2015, ambos de tendencia liberal.

\section{Quebec: de la afirmación nacional a un régimen de ciudadanía}

En este apartado se dirige la mirada al interior de Quebec, especialmente al mapa de su diversidad cultural y a los mecanismos de los que se ha dotado para gestionarla. En particular, se hace un breve recorrido histórico de la política quebequense en materia de inmigración, integración y de pluralismo, a fin de analizar si esta nación se ha dotado de una estructura institucional propia en su política de gestión cultural o si ha seguido las señas del multiculturalismo canadiense.

La provincia más grande de Canadá se compone actualmente de una mayoría francófona ( $81 \%$ ), una minoría anglófona, diez naciones amerindias y la nación inuit, así como de un importante contingente de inmigrantes 
recientes que provienen de 180 países diferentes en razón de 45 mil cada año, y que hablan 150 lenguas, practican 200 religiones y pertenecen a 120 grupos étnicos (Piché et al., 2007).

Para gestionar la diversidad cultural, a lo largo de los últimos 40 años, Quebec ha ido desarrollando un modelo de inmigración, integración y de relaciones interculturales, para facilitar la convivencia y la cohesión social entre los distintos grupos culturales, los inmigrantes recientes y la sociedad de acogida. A mediados de la década de 1970 comenzó a articularse un marco normativo de gestión de la diversidad que dejaría atrás años de política de afirmación nacional y de actitud asimilacionista.

Asimismo, el gobierno de esta nación empezó a distanciarse del modelo canadiense del multiculturalismo (impulsado, como ya se comentó, en 1971), criticado por no reconocer el particular estatus de la comunidad francófona. Quebec quería evitar los escollos de una política de homogeneidad cultural sin caer en los efectos perversos que algunos le atribuían, correcta o incorrectamente, al multiculturalismo, tales como la folklorización de las culturas, yuxtaposición estática de diversos grupos y promoción de prácticas antidemocráticas bajo el manto de un relativismo cultural (McAndrew, 2003).

Poco a poco, Quebec fue dando forma a una serie de políticas e instituciones democráticas que conviene mencionar: la Charte québécoise des droits et libertés de la personne (Carta de Derechos Humanos y Libertades de Quebec) de 1975, con base en la cual se reconoce el derecho de los miembros de comunidades étnicas a mantener su propia vida cultural y se establece el respeto por las libertades individuales, la solidaridad y la democracia igualitaria entre hombres y mujeres, así como la adopción en 1977 de la Charte de la langue française (Carta de la Lengua francesa), conocida como Ley 101, que instaura el francés como lengua oficial y común de la esfera pública.

A pesar de que se acentúa el carácter mayoritariamente francófono de la sociedad quebequense, no se hace en detrimento de las comunidades políticas nacionales situadas en su territorio, como la minoría anglófona, las Primeras Naciones y la comunidad inuit. Como bien explica Linda Cardinal (2011), la adopción de esta política significó para algunos estudiosos acoger una posición radical alejada de la dinámica de construcción de puentes y una afrenta a los principios liberales de los derechos individuales; mientras que para otros (Cardinal, 2011) se consideró el inicio de una serie de pasos hacia la integración, al ser la vía de apertura a procesos participativos.

Desde ese momento se continuó poniendo énfasis en la idea de que la lengua francesa es una condición mínima del ejercicio de la ciudadanía común y una herramienta de la democracia. Así lo confirma Giroux (1997: 137): "Es 
importante que la lengua francesa aparezca siempre y ante todo como una condición del ejercicio de los derechos del ciudadano, la nación no puede pretender ser un foro de discusión y toma de decisiones sin la existencia de una comunidad de lengua".

Algunos años después se emprendería un proceso de elaboración de una política de convergencia cultural. El gobierno de Quebec pretende restablecer el estatus de la mayoría francófona no sólo en el escenario sociolingüístico, sino también busca que quede reflejado en un plan sobre la inmigración y la integración, dado que ambos han devenido "inextricablemente ligados al destino de la nación quebequense” (Gagnon y Iacovino, 2003: 397).

En un documento oficial, La Politique québécoise du développement culturel (Gouvernement du Québec, 1978: 79), se afirma que "entre la asimilación lenta o brutal y la conservación de particularidades incluidas en murallas segregacionistas, hay otra voz posible: la del intercambio en el seno de la cultura quebequense". En 1981, Quebec reitera su adhesión al ideal de la convergencia cultural como queda plasmado en un documento titulado Autant de façons d'être Québécois, el cual privilegia un enfoque de acercamiento intercultural entre el grupo mayoritario francófono y las minorías etnoculturales.

Algunas voces críticas, como la de Constantinides (1985), señalaron que estas políticas impulsadas por el PQ tenían un referente comunitario y etnocéntrico que jerarquizaba a la sociedad, colocando a la cultura y a la lengua del grupo mayoritario en un ámbito superior al resto de los residentes en Quebec; otros especialistas, como Gagnon e Iacovino (2003: 398) y Harvey (1998), en cambio, enfatizaron en la idea de convergencia que fomenta este modelo de integración y que le da una connotación distinta a la del multiculturalismo - mosaico- canadiense.

Gagnon e Iacovino (2003: 398) señalan también que con este documento comenzaba a configurarse un modelo quebequense de interculturalismo, al subrayar que la integración de los inmigrantes pasa por la promoción de intercambios y de interacciones entre las diferentes colectividades que forman la sociedad (Gagnon et al., 2014: 9).

Una respuesta a estas críticas vino de la mano de la adopción oficial de la declaración política Au Québec pour bâtir ensemble. Énoncé de politique en matière d'immigration et d'intégration de 1990. El Parti Libéral du Québec había llegado al poder en 1985 y frente a la política anterior centrada en un modelo de representación cultural y política cimentada en la lengua y en el proyecto independentista, se concentra en la promoción de los derechos individuales de los inmigrantes y de las minorías etnoculturales. Cuatro años más tarde ganó nuevamente las elecciones e inició un cambio de rumbo al 
adoptar una política que promovía un nuevo modelo de integración, conocido como la cultura pública común (Harvey, 1991).

El nuevo camino tiene un tono más liberal y una disposición a reconocer el mestizaje identitario; "el concepto de comunidades culturales cede gradualmente el lugar al de quebequenses de todos los orígenes, llamados a mediatizar las pertenencias diversas, tanto individuales como comunitarias, en un espacio cívico definido esencialmente como procesal" (Karmis, 2003: 331).

El Énoncé de politique en matière d'immigration et d'intégration constituye el inicio de lo que se conoce como "contrato moral" de integración, donde se establecen los derechos y deberes tanto de los inmigrantes como de la sociedad de acogida. Este documento es relevante porque se le considera el primero que articula una política del interculturalismo (Rocher et al., 2007), aun cuando el concepto no aparece. Establece que a) Quebec es una sociedad cuya lengua común de la vida pública es el francés; $b$ ) Quebec es una sociedad democrática donde se atiende y favorece la participación y la contribución de todos; c) Quebec es una sociedad pluralista, abierta a diversas aportaciones culturales con el sólo límite que impone el respeto de los valores democráticos fundamentales y la necesidad del intercambio comunitario (Gouvernement du Québec, 1990: 15-16).

Estos presupuestos dejan clara la apuesta por una política de integración, que es una de las notas características del pluralismo cultural, pero que adquiere diferentes matices según el modelo de pluralismo que se adopte.

En este caso, el contrato moral de integración pone el acento en un ideal más cívico que cultural y se desdibujan los rastros de asimilacionismo, abriéndose el enfoque hacia los intercambios interculturales; se adoptan medidas de lucha contra el racismo, la intolerancia y la discriminación. La sociedad de acogida habrá de ser definida en un sentido más amplio y de carácter más territorial y político, la constituida por todos aquellos que residen en el territorio y que se adhieren a los elementos centrales antes descritos (sociedad democrática y pluralista en la que el francés es la lengua pública común y oficial).

Esta posición no estará exenta de críticas. A lo largo de la última década del siglo pasado se emprendieron numerosos debates para buscar una definición de un conjunto más sustantivo de valores comunes "llamado sucesivamente cultura pública común, cultura cívica, cultura societal, espacio público común" (Karmis, 2003: 331). Las grandes preguntas eran: ¿Qué es una cultura? ¿Cuáles son los contornos de la vida pública? ¿Qué puede ser común en las sociedades de individuos? "¿Lo común tiene la densidad de una identidad o la ligereza de una afiliación pasajera y rescindible?” (Gervais et al., 2008: 63). 
En dicho contexto, académicos como Micheline Labelle (2008), AlainG. Gagnon y Raffaele Iacovino (2003) dirigen su atención a la idea de una ciudadanía quebequense como modelo de integración; esta orientación sigue la estela de la cultura pública común como modelo de integración, pero a diferencia de ella enfatiza en un equilibrio entre los requerimientos para la unidad como una base identitaria y el reconocimiento de las culturas minoritarias.

El objetivo es adoptar un modelo que no sea asimilacionista, sino defensor del pluralismo cultural, sin caer en el relativismo cultural ni en la fragmentación. Se valora "la deliberación, el entendimiento mutuo y, en general, el diálogo, como características fundamentales de la vida democrática en la esfera de la sociedad civil y reviste una función instrumental, mediante una concepción coherente y participativa de la ciudadanía" (Gagnon et al., 2003: 401).

De esta manera, se desalientan las posibilidades de encierro y confinamiento en un gueto, porque el "reconocimiento de identidades culturales particulares es de hecho el reconocimiento del derecho y la obligación de participar en la polis, no el reconocimiento de la cultura como existente en comunidades autónomas en un vacío espacio temporal" (Gagnon et al., 2003: 409).

El Ministère des Relations avec les Citoyens et l'Immigration (MRCI), creado en 1996 en sustitución del Ministère des Affaires internationales, de l'immigration et des Communautés culturelles, organizó en el año 2000 el Forum national sur la citoyenneté et l'intégration, cuyos principales objetivos eran: a) presentar y dar a conocer las orientaciones en materia de ciudadanía quebequense y de integración; $b$ ) definir las formas de acción más convenientes para hacer comprender y apreciar la ciudadanía quebequense, así como incrementar la participación cívica; y c) asociar a los interlocutores gubernamentales, socioeconómicos, culturales y regionales, así como a las comunidades y las naciones autóctonas a los ejes de estas medidas de acción (Ministère des Relations avec les citoyens et l'Immigration, 2000).

Esta iniciativa gubernamental dio lugar a muchas críticas, entre ellas, la de fomentar una visión de la ciudadanía tradicional y homogénea; la falta de reconocimiento de la diversidad de la sociedad quebequense y de los deberes de Estado al respecto; así como un excesivo acento propagandístico del programa soberanista.

En 2001 se creó la Commission des États généraux sur la situation et l'avenir de la langue française au Québec (CÉGSALFQ), que vuelve a recuperar la idea de la ciudadanía quebequense, recomendando al gobierno su oficialización. El propósito era concebir a la lengua francesa como un elemento 
central de integración, participación e igualdad de oportunidades; no verlo como un rasgo propio de la mayoría, sino como atributo de todos los quebequenses, independientemente de su origen.

A pesar de que el gobierno no hizo suyas las recomendaciones de esta comisión, algunos estudiosos como Gagnon et al. (2003) siguieron insistiendo en la necesidad de reflexionar colectivamente sobre la ciudadanía y la gestión de la diversidad.

El gobierno liberal bloqueó las iniciativas relacionadas con la recuperación del énfasis en la ciudadanía, y como muestra simbólica, en 2005 , cambió el nombre del ministerio volviendo a la idea original: Ministère de l'Immigration et des communautés culturelles (MICC), cuyos programas son progresivamente reorientados hacia las comunidades culturales.

El plan de acción del MRCI para el periodo 2004-2007 tenía como objetivo asegurar la plena participación de las comunidades culturales en el desarrollo de Quebec; este acercamiento pluridimensional introduce nuevamente la dimensión cultural en la gestión gubernamental (Bouchard, 2013). François Rocher y Micheline Labelle (2010) señalan que hay dos ejes de este plan que aluden directamente a la integración.

El primero se refiere a una serie de medidas que pretenden favorecer una inserción rápida y permanente de los quebequenses de las comunidades culturales en el empleo. El segundo agrupa una serie de medidas dirigidas a valorar las aportaciones de las comunidades culturales al desarrollo social, económico y cultural de Quebec, y a favorecer el diálogo intercultural, la apertura a la diversidad y la lucha contra el racismo y la xenofobia (Ministére des Relations avec les Citoyens et de l'Immigration, 2004).

A pesar de los esfuerzos políticos por evitar la discriminación y el racismo y fomentar la integración, entre marzo de 2006 y junio de 2007 la repercusión mediática que alcanzaron diversos casos de acomodo razonable asociados a diferencias culturales generó temores y sentimientos de amenaza en la población.

Los actores políticos entraron en una dinámica en la que prácticamente todos los días debían pronunciarse sobre esta cuestión. Ante la posible extensión e incremento de una percepción negativa sobre la diversidad cultural y el acomodo de algunas de sus prácticas, el primer ministro de Quebec, Jean Charest, nombró el 8 de febrero de 2007 una comisión autónoma e independiente encargada de consultar a la ciudadanía y de hacer un informe sobre las prácticas de acomodos razonables entre las diferentes culturas que conviven en Quebec.

La presidencia de la comisión quedó integrada por el sociólogo Gérard Bouchard y por el filósofo Charles Taylor. La Comisión Bouchard-Taylor tenía 
como mandato expreso diseñar un mapa de las prácticas de armonización intercultural que tienen lugar en Quebec; analizar las experiencias de otras sociedades; poner en marcha una consulta ciudadana; y formular recomendaciones al gobierno, para que estas prácticas se realizaran de acuerdo con los valores de la sociedad quebequense: pluralidad, democracia e igualdad.

Una vez hechas sus tareas, la comisión presentó en la primavera de 2008 el informe final denominado Fonder l'avenir. Le temps de la conciliation (Bouchard y Taylor, 2008). Laforest resume el espíritu del documento indicando que el objetivo es "aproximar las inquietudes de una mayoría heredera del Canadá francés y del catolicismo y las minorías culturales y religiosas, a fin de que estas inquietudes no se transformen en soledades encerradas las unas sobre las otras" (Laforest, 2010: 127).

Las dos coordenadas centrales del informe final son, por una parte, la defensa del modelo de pluralismo integrador -también denominado interculturalismo-, cuyos elementos constitutivos son la protección de derechos, el sostenimiento del núcleo francófono, la participación y la reciprocidad; y, por la otra, el principio de laicidad abierta (Wences, 2013). Este informe constituye un punto de referencia importante porque delinea claves centrales del interculturalismo quebequense (Gagnon et al., 2014).

Los desacuerdos con el contenido de dicho informe provinieron de distintos frentes. Algunos lo consideraban bastante débil respecto a la afirmación de la identidad del pueblo quebequense. La entonces líder de la oposición -y posteriormente primera ministra- Pauline Marois dejó clara una postura que más tarde, ya en el poder, intentaría asentar políticamente: no había que contentarse con sólo hablar de cultura, lengua y laicidad como lo hacía el informe -replicó al primer ministro-, sino inscribir en las leyes los principios del predominio de la lengua francesa (reforzando la Ley 101), la promoción de la cultura quebequense y la laicidad de las instituciones.

Días después, Jean Charest dio carpetazo a una de las recomendaciones centrales de la Comisión Bouchard-Taylor: la de formalizar oficialmente el interculturalismo. Su argumento era que dicho concepto ya estaba incluido en la política gubernamental de 1990 y declaró que no le quedaba claro en qué "el interculturalismo entraba en colisión con el multiculturalismo canadiense” (Assemblée Nationale du Québec, 27 de mayo de 2008).

En septiembre de 2012, el Parti Québécois ganó las elecciones de nuevo y al año de haber llegado al poder, Maurois y su gobierno lanzaron la iniciativa de la Charte des valeurs québécoises et de la lä̈cité, Loi 60 (Carta de valores quebequenses y de la laicidad, Ley 60), la cual tenía como objetivo, entre otros, restringir el uso público de símbolos e insignias religiosos, que se 
justificaba, entre otras razones, en una crítica al Parti Libéral du Québec, en el sentido de que éste no se había ocupado de responder a las preocupaciones de los ciudadanos en relación con las demandas de acomodo razonable y de dar respuesta a las recomendaciones de la Comisión Bouchard-Taylor.

La propuesta se inspira en el modelo de laicismo francés que reivindica la neutralidad del Estado ante los signos religiosos y se aleja de las aspiraciones por integrar a los inmigrantes, mediante la preservación de su identidad cultural y religiosa. Sus medidas suponen un retroceso en el camino del interculturalismo. Las duras críticas que recibió ocuparon numerosos espacios en los medios de comunicación.

La contundente reacción ante esta iniciativa provino de varias direcciones. Se manifestaron en contra tanto los grupos minoritarios, como los sectores más progresistas y laicos de la sociedad quebequense. Reaccionaron fuertemente investigadores universitarios, entre ellos Jocelyn Maclure (2013), quien afirma que Quebec no tiene necesidad de una Carta sobre la laicidad, porque el Estado ya es laico y neutro respecto a las religiones; señala que una iniciativa como ésta alimenta una falsa percepción sobre la supuesta insuficiente capacidad de los principios de la cultura pública común para gestionar correctamente la diversidad moral y religiosa de Quebec; y considera que la prohibición general de los trabajadores del Estado porten símbolos religiosos visibles es inequitativo e inoportuno, pues lo relevante son sus actos, no su apariencia.

Voces opositoras provinieron también de reconocidos intelectuales francófonos de simpatía independentista, así como de distinguidos políticos del PQ, como Jacques Parizeau, ferviente defensor del independentismo y que enarboló la bandera del referéndum de 1995. El copresidente de la Comisión de consulta sobre las prácticas de acomodo relacionadas con las diferencias culturales y defensor del interculturalismo, Gérard Bouchard, envió una dura carta a La Presse criticando a Bernard Drainville, entonces ministro y responsable del proyecto de la Charte des valeurs, e instándole a que dimitiera de su escaño por haber "multiplicado las declaraciones incendiarias y falsas para sublevar la mayoría quebequense contra las minorías y los inmigrantes”.

En una entrevista realizada por Radio Canadá, tanto Gérard Bouchard como Charles Taylor afirmaron que la Charte des valeurs restringe los derechos fundamentales, ahonda en la discriminación y fragmenta social y jurídicamente a los habitantes de Quebec. El primero de ellos señaló, además, que su implantación quebranta duramente a la sociedad, agrandando las distancias entre la mayoría y las minorías. El segundo argumentó que la supuesta neutralidad del Estado que dicen enarbolar los promotores de la Charte del 
valeurs esconde, en el fondo, una política que favorece a unas religiones sobre las otras; afirmó sentirse muy consternado por la división y el odio que esta política podría generar entre los inmigrantes y la sociedad de acogida; y dijo que la propuesta del gobierno era una sociedad estrecha y excluyente.

Dieciocho meses después de llegar al poder, la líder del PQ, Pauline Marois, convocó a elecciones generales y no sólo fue derrotada en su propia circunscripción, sino además su partido sufrió una disminución del $7 \%$ del total de los votos recibidos en la elección de 2012. Los liberales obtuvieron cerca del $41 \%$ de los votos. Philippe Couillard, designado primer ministro de Quebec, declaró en su discurso de victoria: "Debemos concentrarnos en lo que nos une. Lo que nos une nos hace más fuertes. Y digamos juntos con pasión: todos estamos orgullosos de ser quebequenses". Una de las primeras medidas consistió en que el Ministère de l'Immigration et des communautés culturelles cambiara de denominación en abril de 2014, para llamarse Ministère de l'Immigration, de la Diversité et de l'Inclusion.

Entre las funciones de este Ministerio, y que entraron en vigor el $1^{\circ}$ de junio de 2014, se encuentra la de favorecer la integración lingüística, social y económica de los inmigrantes en la sociedad quebequense; favorecer la plena participación de las comunidades culturales en la sociedad; fomentar el pluralismo; y facilitar el acercamiento intercultural.

En diciembre de 2014 el gobierno de Quebec abrió una convocatoria de consulta pública para elaborar, en conjunto con la ciudadanía, la política en materia de diversidad cultural, inmigración, inclusión y participación. Tras esta consulta, en la cual participaron, entre otros, reconocidos autores de la llamada Escuela Canadiense de la Diversidad, el 7 de marzo de 2016 el Ministerio de Immigration, Diversité et Inclusion dio a conocer el informe Ensemble, nous sommes le Québec (Juntos, somos el Quebec).

En dicho documento, que prevé medidas para ser implementadas a lo largo de cinco años, se alude expresamente "a la necesidad de dotar a Quebec de una nueva política y de afirmar al interculturalismo quebequense como el modelo pluralista que guía el proyecto de vivir juntos" (Gouvernement du Québec, 2016: X).

Por primera vez, el interculturalismo queda definido expresamente como política oficial y se enfatiza en el reconocimiento y valorización de:

una concepción plural y dinámica de la identidad quebequense, una lengua pública común, el francés, el respeto a los derechos y libertades de la persona, una ética del diálogo y de la mediación, así como en una apuesta por la integración basada en un compromiso compartido entre la sociedad y las personas inmigrantes (Gouvernement du Québec, 2016: 35). 
Asimismo, tiene como fin "la lucha contra la discriminación" y reconoce "la importancia de los acercamientos interculturales y de la necesidad de la plena participación de los y las quebequenses de todos los orígenes" (Gouvernement du Québec, 2016: 35).

\section{Conclusiones}

La primera cuestión que conviene resaltar es que tanto el interculturalismo como el multiculturalismo son nociones polisémicas que requieren niveles de análisis diferentes. Por un lado, configuran teorías políticas que buscan dar respuesta a los postulados derivados de la extendida visión del Estado nación uniformador y asimilacionista, la cual considera que la esfera pública debe ser culturalmente homogénea. Por otro, engloban un conjunto de medidas y políticas públicas institucionales dirigidas a gestionar la diversidad etnocultural. Y, finalmente, pueden configurarse como un modelo de Estado, lo que implicaría su regulación constitucional.

En el escenario canadiense, el interculturalismo y el multiculturalismo hunden sus raíces en el pluralismo cultural; pero se trata de dos modelos distintos tanto en el plano normativo como en la dimensión política, cuya distancia también se explica por la historia particular de Quebec y Canadá, así como por la histórica relación entre ambas naciones (Taylor, 2012). Ahora bien, sobre las diferencias entre las dos hay diversas percepciones que varían en intensidad, desde quienes sostienen que las discrepancias son de matiz hasta quienes consideran que su fin último les hace cobijar principios dispares.

En el escenario quebequense, el interculturalismo como política tuvo que esperar a marzo de 2016 para ser incorporada oficialmente en un documento gubernamental. Sin embargo, los antecedentes mencionados en este trabajo permiten afirmar que desde tiempo atrás se estaba gestando un acervo de elementos que, observados individualmente o en conjunto, le iban otorgando sustancia: diálogo intercultural; convivencia intercultural; apertura al intercambio cultural; cultura quebequense de tradición francófona; acercamiento entre sociedad de acogida y minorías de diversas comunidades; educación intercultural; tolerancia, respeto, reciprocidad y reconocimiento entre los grupos; política de integración, contrato moral, cultura pública común, cultura cívica común.

De acuerdo con estos descriptores, presentes a lo largo de leyes y políticas referidas en las páginas de este trabajo (véase el Cuadro $1^{1}$ ), es posible asentar que Quebec ha ido configurando "una constitución informal” determinante

1 Se encuentra en el Anexo, al final del presente artículo (Nota de los editores). 
para las relaciones entre la mayoría y la minoría. Es verdad que Quebec no ha reconocido la reforma constitucional de 1982, pero eso no le ha impedido dotarse de leyes y políticas públicas que permiten a los ciudadanos de esta nación darle un "sentido a su experiencia colectiva en el seno del conjunto político canadiense” (Gagnon, 2010: 248).

En los últimos años, Quebec ha adoptado una serie de medidas institucionales y responsabilidades asociadas con políticas sobre la tolerancia y el respeto a la diferencia dentro de un entorno social francófono, a pesar de los vaivenes entre quienes apuestan por el multiculturalismo, los defensores del interculturalismo y aquellos que enfatizan modelos con tintes asimilacionistas.

Las iniciativas, comisiones, programas y acuerdos que se han mencionado a lo largo de este artículo dan cuenta -a pesar de las oscilaciones presentadas según quien detente el poder y cuál sea su relación con el gobierno federalde la paulatina configuración de un modelo de interculturalismo propio del Quebec (Bouchard, 2013), el cual queda bien reflejado en el reciente compromiso político Ensemble, nous sommes le Québec.

Este modelo de gestión de la diversidad se ha ido configurando con una serie de valores, principios y políticas, entre las cuales pueden destacarse: la promoción de la lengua francesa; el énfasis en los derechos; el respeto a la diversidad; la lucha contra la discriminación; el lugar otorgado a la cultura mayoritaria francófona; el reconocimiento de minorías etnoculturales en un marco pluralista; la protección de valores fundamentales como son la democracia, la igualdad hombre-mujer, la no discriminación y la laicidad basada en el respeto a la igualdad moral de los individuos y en la protección de la libertad de conciencia y de culto; el imperativo de la integración; la búsqueda de una voz que medie entre la asimilación y la fragmentación; la necesidad de una dinámica de interacciones y de intercambios intercomunitarios; el desarrollo de una cultura pública común y de una pertenencia quebequense; la participación de todos los habitantes en la vida cívica y política; el principio de reciprocidad en el proceso de integración de los inmigrantes, especialmente en relación con los acomodos; y prácticas de armonización mediante la educación a la ciudadanía para que actúe responsablemente.

Ahora bien, de acuerdo con diversos académicos, como Gagnon, Milot, Seidle y Boucher (2014), estos avances son incompletos si no van acompañados de políticas públicas convenientemente articuladas con el interculturalismo; y de lazos intercomunitarios de confianza que pueden dotar de fuerza al interculturalismo, la cual sólo será posible a través del fomento "de una cultura común que integre la diversidad” (González Ulloa, 2014: 198); es decir, de una ciudadanía activa que pueda conducir "a un estatuto legal, al acceso al 
ejercicio de los derechos, a la participación de todos en el seno de la comunidad política y al sentimiento de pertenencia a un territorio, el del Quebec" (Rocher y Labelle, 2010: 202).

Algunos especialistas como Gagnon (2013) insisten también en la importancia de la habilitación como vía para favorecer el diálogo y sentar las bases de una convergencia política. Dicho esto, aún queda camino por recorrer para ver los resultados de la configuración política y jurídica del interculturalismo, así como los alcances de su aceptación social.

Por último, es pertinente seguir insistiendo en que en contextos democráticos y plurales el debate normativo y político sobre el reconocimiento de la diferencia así como sobre los modelos y políticas pluralistas de gestión de la diversidad cultural es extremadamente complejo y conviene no simplificarlo con etiquetas reduccionistas, las cuales muchas veces tergiversan los contenidos, extienden los prejuicios, obstaculizan los esfuerzos para la convivencia y la cohesión social, y pueden fomentar la fragmentación. Como bien afirma Laforest (2010: 136), avanzaríamos mucho si se reconociera que la convivencia en la diferencia "puede hacerse combinando elementos de convergencia y de desacuerdo”.

\section{Referencias}

Assemblée national du Québec (2008), Journal des débats, martes 27 de mayo, núm. 40, vol. 88.

Bauer, Julien (1994), Les Minorités au Québec, Montréal: Boréal.

Bissoondath, Neil (1995), Le marché des illusions: un essai sur le multiculturalisme, Montréal: Boréal.

Bouchard, Gérard (2012), L’interculturalisme, Montréal: Boréal.

Bouchard, Gérard (2013), "What is Interculturalism”, en Alain-G. Gagnon y José María Sauca [eds.], Negotiating Diversity: Identity, Pluralism and Democracy, Brussel: Peter Lang.

Bouchard, Gérard y Charles Taylor (2008), Fonder l'avenir. Le temps de la conciliation, Québec: Gouvernement du Québec.

Bourque, Gilles et al. (2000), "Multiculturalisme, pluralisme et communauté politique: le Canada et le Québec", en Michael Elbaz y Denise Helly [eds.], Mondialisation, citoyenneté et multiculturalisme, Québec: Les Presses de l'Université Laval y L'Harmattan.

Brouillet, Eugénie (2005), La négation de la nation. L'identité culturelle québécoise et le fédéralisme canadien, Québec: Septentrion.

Brouillet, Eugénie (2008), "La evolución de las relaciones jurídicas entre Canadá y Quebec o la difícil cohabitación de dos lógicas nacionales", en Istor. Revista de Historia Internacional, vol. VIII, núm. 32, México: Centro de Investigación y Docencia Económica. 
Cardinal, Linda (2011), “Fédéralisme et langue. L'incidence du fédéralisme d'ouverture sur les régimes linguistiques canadien et québécois", en Michel Seymour y Guy Laforest [dirs.], Le fédéralisme multinational. Un modèle viable?, Bruxelles: Peter Lang.

Constantinides, Stephanos (1985), "Ethnicité et pluralisme culturel”, en Revue internationale d'action communautaire, núm. 14, Montreal: érudit.

Forbes, Donald (2007), "Immigration and Multiculturalism vs. Quebec Separatism: An Interpretation of Canadian Constitutional Politics since 1968”, ponencia presentada en la American Political Science Association, agosto.

Gagnon, Alain-G. (2003), "El expediente constitucional Quebec-Canadá”, en Alain-G. Gagnon [comp.], Quebec: Estado y Sociedad, Guadalajara, México: Universidad de Guadalajara.

Gagnon, Alain-G. (2008), "La evolución del federalismo canadiense”, en Istor. Revista de Historia Internacional, vol. VIII, núm. 32, México: Centro de Investigación y Docencia Económica.

Gagnon, Alain-G. (2010), "La diversité et la place du Québec au sein de la fédération canadienne", en Bernard Gagnon [dir.], La diversité québécoise en débat. Bouchard, Taylor et les autres, Montréal: Éditions Québec Amérique y Chaire de recherche du Canada en études québécoises et canadiennes, colección Débat.

Gagnon, Alain-G. (2013), Época de incertidumbres. Ensayo sobre el federalismo y la diversidad nacional, Valencia: Tirant lo blanch.

Gagnon, Alain-G. y Raffaele Iacovino (2003), "El proyecto intercultural quebequense: expandiendo los límites de la ciudadanía”, en Alain-G. Gagnon [comp.], Quebec: Estado y Sociedad, Guadalajara, México: Universidad de Guadalajara.

Gagnon, Alain-G. y Jean-Charles St. Louis (2013), "La Commission Laurendeau-Dunton et le devoir de repenser la diversité canadienne”, en Thèmes canadiens, otoño, Montreal: Association d'études canadiennes.

Gagnon, Alain-G., Milot Micheline, Seidle F. Leslie y François Boucher (2014), "Rapport présenté au ministère de l'Immnigration, de la Diversité et de l'Inclusion en vue d'élaborer un nouvel énoncé de politique", Montreal. Disponible en: http://www. midi.gouv.qc.ca/publications/fr/recherches-statistiques/ETU_AmenagDiversite_ GagnonMilotSeidleBoucher.pdf [28 de octubre de 2014].

Gervais, Stéphan et al. [dirs.] (2008), Du tricoté serré au métissé serré? La culture publique commune au Québec en débats, Québec: Université Laval.

Giroux, France (1997), "Le nouveau contrat national est-il possible dans une démocratie pluraliste? Examen comparatif des situations française, canadienne et québécoise”, en Politique et Sociétés, vol. 16, núm. 3, Québec: Société Québécois de Science Politique.

González Ulloa Aguirre, Pablo Armando (2014), "El multiculturalismo en Canadá: la redefinición de las políticas de la inclusión y sus teóricos", en Norteamérica, enerojunio, vol. 9, núm. 1, México: UNAM. Disponible en: http://www.revistas.unam.mx/ index.php/nam [8 de marzo de 2016].

Gouvernement du Québec (1978), La Politique québécoise du développement culturel, Ministère d'État au Développement culturel, Éditeur officiel du Québec.

Gouvernement du Québec (2016), Ensemble, nous sommes le Québec. Disponible en: http://www.midi.gouv.qc.ca/publications/fr/dossiers/Politique_ ImmigrationParticipationInclusion.pdf [10 de marzo de 2016]. 
Harvey, Julien (1998), “Le Québec, société plurielle en mutation?”, en Globe. Revue internationale d'études québécoises, vol. 1, núm. 1, Québec: érudit.

Harvey, Julien (1991), "Culture publique, intégration et pluralisme”, en Relations, núm. 574, Québec: Centre Justice et Foi.

Helly, D. (2005), Le multiculturalisme canadien: des leçons pour la gestion de la diversité culturelles?, Informe presentado al Ministère Patrimoine canadien, Canadá: Institut National de la Recherche Scientifique, Centre Urbanisation, Culture et Société. Disponible en: http://www.pch.gc.ca/pcch/pubs/diversity2003/helly_f.cfm [16 de junio de 2011].

Heywood, Andrew (2010), Introducción a la Teoria Política, Valencia: Tirant Lo Blanch.

Karmis, Dimitris (2003), "Pluralismo e identidad(es) nacional(es) en el Quebec contemporáneo: aclaraciones conceptuales, tipología y análisis del discurso", en Alain-G. Gagnon [comp.], Quebec: Estado y Sociedad, Guadalajara, México: Universidad de Guadalajara.

Keating, Michael (2001), Plurinational Democracy: Stateless Nations in a Post-Sovereignty Era, Oxford: Oxford University Press.

Labelle, Micheline et al. (1995), "Pluriethnicité, citoyenneté et intégration de la souveraineté pour lever les obstacles et les ambiguïtés”, en Cahiers de Recherche Sociologique, núm. 25, Montréal: Université du Québec à Montréal.

Labelle, Micheline (2008), "De la culture publique commune à la citoyenneté: ancrages historiques et enjeux actuels", en Stéphan Gervais, Dimitrios Karmis y Diane Lamoureux [dirs.], Du tricoté serré au métissé serré? La culture publique commune au Québec en débats, Québec: Presses de l'Université Laval.

Labelle, Micheline et al. (2011), "Les limites indépassables de l'interculturalisme en contexte canadien: un chemin semé d'embûches", en Actas Symposium international sur l'interculturalisme. Dialogue Québec-Europe, Montréal, 25-27 de mayo. Disponible en: http://www.symposium-interculturalisme.com/pdf/livre_complet_FINAL_ hyperliens.pdf [ 5 de agosto de 2012].

Laforest, Guy (2010), "La Commission Bouchard-Taylor et la place du Québec dans la trajectoire de l'État-nation moderne”, en Bernard Gagnon [dir.], La diversité québécoise en débat. Bouchard, Taylor et les autres, Montréal: Éditions Québec Amérique y Chaire de recherche du Canada en études québécoises et canadiennes, colección Débats.

Laforest, Guy (2014), Un Québec exilé dans la fédération. Essai d'bistoire intellectuelle et de pensée politique, Montréal: Éditions Québec Amérique.

Leman, M. (1999), Le multiculturalisme canadien, Ottawa: Bibliothèque du Parlement, Division des affaires publiques et sociales.

Maclure, J. (2013), “Le projet d'une charte de la laïcité: les raisons d'un sain scepticisme”, en La Revue Tocqueville, vol. XXXIV, núm. 1, Toronto: Toronto University Press.

McAndrew, Marie (2003), “Inmigración, pluralismo y educación”, en Alain-G. Gagnon [comp.], Quebec: Estado y sociedad, Guadalajara, México: Universidad de Guadalajara.

Ministère des Relations avec les Citoyens et l'Immigration (2000), Forum national sur la citoyenneté et l'intégration, Québec: Les Publications du Québec.

Ministère des Relations avec les citoyens et de l'Immigration, (2004), Des valeurs partagées, des intérêts commun: pour assurer la pleine participation des Québécois des communautés culturelles au développement du Québec. Plan d'action 2004-2007, Montréal: Direction des affaires publiques et des communications. 
Piché, Victor et al. (2007), L'immigration au Québec, memoria presentada a la Commission de consultation sur les pratiques d'accommodement reliées aux différences culturelles, Montreal. Disponible en: https://www.mce.gouv.qc.ca/publications/CCPARDC/ rapport-11-piche-victor.pdf [12 de julio de 2014].

Rocher, François, Micheline Labelle, Ann-Marie Field y Jean-Claude Icar (2007), Le concept d'interculturalisme en contexte québécois: généalogie d'un néologisme, Memoria presentada a la Commission de consultation sur les pratiques d'accommodement reliées aux différences culturelles, Montreal. Disponible en: https://www.mce.gouv.qc.ca/ publications/CCPARDC/rapport-3-rocher-francois.pdf [20 de septiembre de 2014].

Rocher, François y Micheline Labelle (2010), "L'interculturalisme comme modèle d'aménagement de la diversité: compréhension et incompréhension dans l'espace publique québécois", en Bernard Gagnon [dir.], La diversité québécoise en debat. Bouchard, Taylor et les autres, Montréal: Québec Amérique y Chaire de recherche du Canada en études québécoises et canadiennes.

Seymour, M. (1999), La nation en question, Montreal: L'Hexagone.

Seymour, Michel (2008), De la tolérance à la reconnaissance, Montréal: Boréal.

Taylor, Charles (1983), "Political Theory and Practice", en Charles Taylor [ed.], Social Theory and Political Practice, Oxford: Clarendon Press.

Taylor, Charles (1992), Rapprocher les solitudes: écrits sur le fédéralisme et le nationalisme au Canada, Québec: Presses de l'Université Laval.

Taylor, Charles (2012), "Interculturalism or multiculturalism", en Philosophy and Social Criticism, vol. 38, núms. 4-5, United Kingdom: Sage.

Tully, James (1999), "Liberté et dévoilement dans les sociétés plurinationales", en Globe. Revue Internationale d'Études Québécoises, vol. 2, núm. 2, Québec: UQAM.

Wences, Isabel (2013), "Cuatro lecciones de la Comisión Bouchard-Taylor: Acomodos razonables, pluralismo integrador, laicidad abierta y participación ciudadana”, en Pedro Chaves et al. [eds.], Crisis del capitalismo neoliberal, poder constituyente y democracia real, Madrid: Traficante de sueños.

Wences Isabel (2015), “¿Por qué debe importarnos la Teoría Política?”, en Isabel Wences [ed.], Tomando en serio a la Teoría Politica, Madrid: CentrodeEstudios Políticos y Constitucionales. 
Anexo

\section{Cuadro 1}

Planes de acción, medidas e informes relacionados con la gestión de la diversidad etnocultural y la construcción de un modelo de interculturalismo

\begin{tabular}{ll}
\hline \multicolumn{1}{c}{ Planes, informes y políticas } & Año \\
\hline Autant de façons d'être Québécois & 1981 \\
\hline Au Québec pour bâtir ensemble & 1990 \\
\hline Forum national sur la citoyenneté et l'intégration & 2000 \\
\hline La diversité : une valeur ajoutée & 2008 \\
\hline Fonder l'avenir. Le temps de la conciliation & 2008 \\
\hline Ensemble, nous sommes le Québec & 2016 \\
\hline Fuente: Elaboración propia. &
\end{tabular}

Isabel Wences. Profesora Titular de Ciencia Política de la Universidad Carlos III de Madrid. Líneas de investigación: diversidad cultural, cultura de la legalidad, sociedad civil, republicanismo e historia de las ideas políticas y pensamiento ilustrado. Publicaciones recientes: "Interculturalism and Republicanism: Is Dialogue Possible?”, en Alain-G. Gagnon et al. [eds.], Negotiating Diversity: Identity, Pluralism and Democracy, Brussels: Peter Lang (2013); "Interculturalismo y republicanismo: cruce de miradas sobre la diversidad cultural”, en Isegoría. Revista de Filosofía Moral y Politica, diciembre, núm. 51, Madrid: Consejo Superior de Investigaciones Científicas (2014); [ed.], “¿Por qué debe importarnos la Teoría Política?” y “Diversidad Cultural y Teoría Política en contextos democráticos”, en Tomando en serio a la Teoría Política, Madrid: Centro de Estudios Políticos y Constitucionales (2015); "Diversidad cultural y acomodos razonables. Una lectura desde la no dominación”, en Foro Interno. Anuario de Teoría Política, vol. 15, Madrid: Universidad Complutense de Madrid (2015).

Recepción: 16 de noviembre de 2014.

Aprobación: 25 de febrero de 2016. 
